\title{
OPTIMALISASI DESAIN PSP-MAP (PIPA SURFACE PENYALUR MATA AIR PANAS) MENGGUNAKAN SOFTWARE POD 1.0 (PHYTON OPTIMIZATION DESIGN) SEBAGAI SALAH SATU UPAYA MEWUJUDKAN INFRASTRUKTUR BERKELANJUTAN DI KAWASAN CISOLOK
}

\author{
Frenly Ferdy Lumalessil, Erwin Fernanda, Firni Agustin Dullah \\ Teknik Geofisika, Fakultas Teknologi Eksplorasi dan Produksi, Universitas Pertamina \\ e-mail : frenlyferdy03@gmail.com
}

\begin{abstract}
Abstrak. Cisolok merupakan salah satu kawasan di Indonesia yang memiliki banyak potensi sumber daya alam maupun geologi. Potensi di kawasan Cisolok yang pernah dikaji dan diteliti sebelumnya adalah manifestasi hidrotermal yang salah satunya berupa mata air panas. Namun, saat ini pemanfaatan mata air panas tersebut hanya sebatas dilakukan di sumber manifestasinya, belum dimanfaatkan secara luas ke rumah penginapan/hotel, homestay, maupun rumah masyarakat setempat. Tujuan dari penelitian ini adalah memberikan desain perencanaan PSP-MAP (pipa surface penyalur mata air panas) berdasarkan karakteristik fluida hidrotermal dan optimalisasi biaya investasi. Adapun metode penelitian yang digunakan ialah metode deskriptif analitis, statistika analitis, dan komparatif analitis. Untuk optimalisasi menggunakan software POD 1.0 (Python Optimalization Design) buatan tim penulis. Jenis data yang digunakan adalah data sekunder dengan mengumpulkan data dari berbagai literatur akuntabel. Hasil penelitian menunjukkan PSP-MAP akan didesain dengan menggunakan bahan dasar HDPE, dilengkapi dengan insulator di dalamnya, serta bahan alumunium untuk bagian luarnya. Hal ini dikarenakan karakteristik kandungan fluida hidrotermal di kawasan tersebut memiliki pH sekitar 8 (netral) dan terdapat sulfat-klorida didalamnya. Ditambah dengan suhu rata-rata pada kandungan fluida hdrotermal berkisar $93^{\circ}-98^{\circ} \mathrm{C}$, sehingga untuk menjaga heat losses yang berlebihan diperlukan insulator didalamnya, serta penggunaan bahan alumunium di bagian luar digunakan untuk menjaga agar PSP-MAP tetap terlindungi. Dari hasil penelitian, biaya optimal terjadi saat ketebalan insulator yang digunakan sebesar $38,2 \mathrm{~cm}$ dan biaya investasi yang dikeluarkan adalah $\$ 142,065$ atau dalam rupiah adalah $\mathrm{Rp}$. 2.009.226,719/m (belum termasuk biaya maintenance) dalam satu tahun. Dengan demikian, diharapkan dengan adanya desain PSP-MAP dapat menjadi landasan baik pemerintah maupun masyarakat setempat untuk mewujudkan infrastruktur berkelanjutan, sehingga manifestasi mata air panas cisolok dapat dimanfaatkan secara luas.
\end{abstract}

Kata Kunci: biaya; Cisolok; hidrotermal; fluida; PSP-MAP.

\begin{abstract}
Cisolok is one of the regions in Indonesia that has a lot of natural and geological potential. Potential in the Cisolok region that has been previously studied and researched is a manifestation of hydrothermal, one of which is a hot spring. However, at present the use of hot springs is only limited to the source of its manifestations, not yet widely used for lodging / hotels, homestays, or local community homes. The purpose of this study is to provide a design plan for PSP-MAP (Hot Spring Channel Surface Pipes) based on hydrothermal fluid characteristics and optimization of investment costs. The research method used is descriptive analysis, statistical analytic, and comparative analytic methods. The purpose of this study is to provide a design plan for PSP-MAP (Hot Spring Channel Surface Pipes) based on hydrothermal fluid characteristics and optimization of investment costs. For optimization using POD 1.0 (Python Optimization Cost) software made by the writer's team. The type of data used is secondary data by collecting data from a variety of accountable literature. The results showed the PSP-MAP will be designed using HDPE-based materials, equipped with an insulator inside, as well as aluminum material for the outside. This is because the characteristic hydrothermal fluid content in the region has a $\mathrm{pH}$ of around 8 (neutral) and there are sulfate-chlorides in it. Added to the average temperature in the hydrothermal liquid content ranging from $93^{\circ} \mathrm{C}$ to $98^{\circ} \mathrm{C}$, so that to maintain excessive heat required an insulator inside, and the use of aluminum material on the outside is used to keep the PSP-MAP protected. From the research results, the optimal cost occurs when the thickness of the insulator used is $38.2 \mathrm{~cm}$ and the investment cost incurred is $\$ 142,065$ or in rupiah is Rp.2.009.226,719/m (not including maintenance costs) in one year. Thus, it is hoped that the PSP-MAP design can become the basis for the government or the community to realize the agreed infrastructure, creating a manifestation of hot springs.
\end{abstract}

Keywords: cost; Cisolok; hydrothermal; fluid; PSP-MAP. 


\section{PENDAHULUAN \\ Latar Belakang}

Indonesia adalah negara yang terletak pada tiga pertemuan lempeng aktif dunia, sehingga Indonesia memiliki kekayaan akan sumber daya alam baik energi maupun geologi. Terdapat salah satu kawasan di Indonesia yang memiliki banyak potensi sumber daya alam maupun geologi, yaitu Cisolok. Potensi di kawasan Cisolok yang pernah dikaji dan diteliti sebelumnya adalah manifestasi hidrotermal yang salah satunya berupa mata air panas. Hal ini memang didukung dengan keadaaan geologis Cisolok yang dikontrol oleh struktur berarah timur laut - barat daya dan barat laut tenggara (Abdillah dkk., 2017). Namun, saat ini pemanfaatan mata air panas tersebut hanya sebatas dilakukan di sumber manifestasinya, belum dimanfaatkan secara luas ke rumah penginapan/hotel, homestay, maupun rumah masyarakat setempat.

Fluida hidrotermal bertemperatur tinggi sampai sedang $\left(150^{\circ} \mathrm{C}-225^{\circ} \mathrm{C}\right)$ telah lama digunakan di beberapa negara maju seperti Jepang, Belanda, Swiss, dan beberapa negara Eropa lainnya, sebagai penghangat ruangan dan air di kamar mandi. Di Indonesia sendiri yang memiliki kekayaan akan potensi panas bumi, belum memanfaatkan secara maksimal dalam menghangatkan ruangan dan air di kamar mandi. Oleh karena itu, dibutuhkan sebuah landasan mengenai desain pipa surface penyalur mata air panas (PSP-MAP) yang sesuai dengan keadaan geologis dan karakteristik fluida hidrotermal di sebuah daerah.

Sebelumnya telah dilakukan beberapa penelitian seperti analisis karakteristik fluida, analisis heat losses pada gas hidrotermal, optimasi pipa penyalur geothermal, analisa potensi panas bumi, dan lain-lain. Pada penelitian kali ini, menentukan desain PSP-MAP yang cocok di daerah Cisolok, berdasarkan literatur penelitan sebelumnya serta optimalisasi biaya investasi. Tujuan penelitian ini adalah membuat desain PSP-MAP berdasarkan analisis karakteristik fluida hidrotermal untuk pemilihan bahan dasar material PSP-MAP, Mencari nilai ketebalan insulator PSP-MAP minimal yang dapat menekan laju heat losses, dan menghitung biaya investasi minimum dalam pembuatan PSPMAP.

\section{Kondisi Geologi Cisolok}

Pada umumnya batuan di Cisolok tergolong pada batuan berumur Tersier dan batuan berumur Kuarter. Terdapat tiga sesar utama yang berarah timur laut-barat daya, timur- barat dan hampir utaraselatan di daerah Cisolok. Sesar dengan arah timur laut-barat daya berumur Tersier yang mengontrol pembentukan cekungan Tersier dan masih aktif mengontrol pengendapan, aktifitas vulkanik serta proses erosi di daerah Cisolok. Struktur termuda (Plistosen) yang berkembang di Cisukarame berarah utara-selatan, sedangkan struktur yang mengontrol pemunculan manifestasi merupakan struktur lebih tua berarah timur laut-barat daya sehingga perlu diketahui lokasi dan polanya. Sesar berarah timurbarat memotong sedimen berumur Miosen atas tetapi tidak berhubungan dengan aktifitas geothermal saat ini. Perpotongan sesar berarah hampir utara-selatan dengan sesar berarah timur laut-barat daya merupakan zona penting karena berhubungan dengan daerah alterasi yang luas (Abdillah dkk., 2017).

Stratigrafi daerah Cisolok dan sekitarnya terdiri dari:

a. Alluvium (Qa) berupa endapan sungai dan endapan undak. Endapan pantai (Qc) setempat berupa dataran pantai, gosong pasir dan batugamping terumbu.

b. Batugamping (Tmtl) anggota dari Formasi Citarate, terletak di bagian bawah, berumur Miosen Awal, memiliki ciri - ciri batugamping terumbu dan mengandung pecahan kuarsa dan feldspar, terendapkan pada lingkungan laut.

c. Breksi Tapos (Qbv), berumur Miosen Akhir, berupa breksi gunungapi bersusun andesit basalt dan aglomerat. Breksi ini menjemari dengan lava Halimun.

d. Dasit (Tmda) berumur Miosen Akhir, bersusun dasit atau liparit, terbentuk retas atau trobosan kecil berbentuk 'stock'

e. Tuff Citorek (Tpv) berumur Pliosen, memiliki ciri endapan epiklastik, tufan bersusun batu gamping dan dasit. Tuf ini diduga selaras di atas Formasi Cimanceuri

Mengenai peta lokasi sampling air daerah Cisolok ditunjukkan sebagai berikut: 


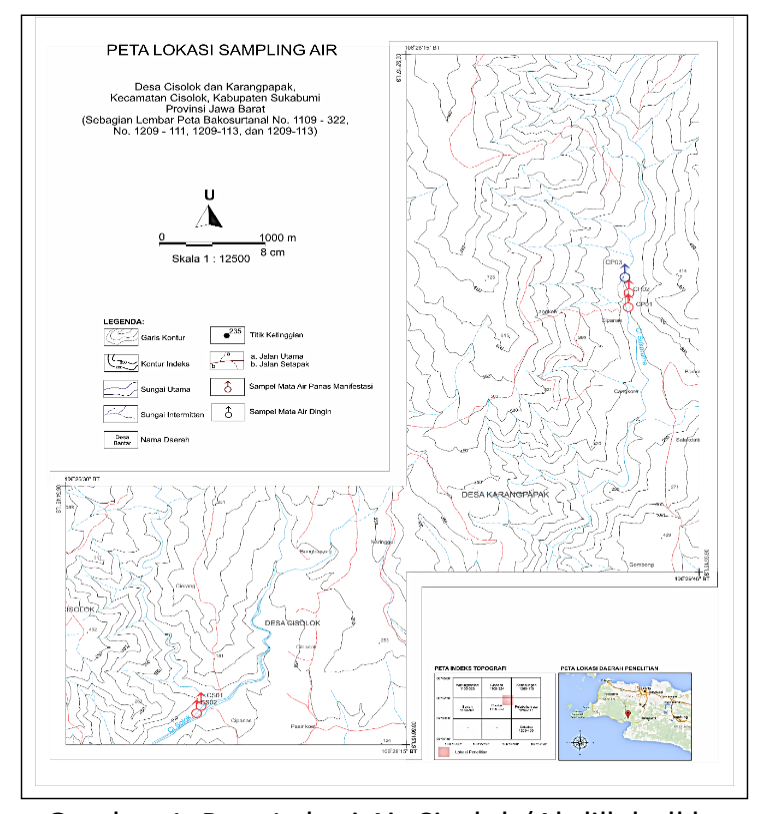

Gambar 1. Peta Lokasi Air Cisolok (Abdillah dkk., 2017)

\section{Fluida Hidrotermal Cisolok}

Aliran fluida dalam pipa mengikuti kaidah hukum kekekalan energi antara dua titik dalam aliran fluida dan dinyatakan bahwa energi masuk dengan kerja yang dilakukan fluida sama dengan energi yang keluar Energi dalam $(U)$ berupa vibrasi energi rotasi, dan energi translasi molekul-molekul fluida. Harga tersebut adalah relatif dan dianggap nol. Sedangkan yang keluar yaitu energi dalam, energi kinetik, energi potensial dan tekanan volume. Adapun persamaannya (Halliday dkk., 2007) sebagai berikut:

$$
\begin{array}{r}
U_{1}+\frac{m v_{1}^{2}}{2 g_{c}}+\frac{m g h_{1}}{g_{c}}+P_{1} V_{1}+q-W \\
=U_{2}+\frac{m v_{2}^{2}}{2 g_{c}}+\frac{m g h_{2}}{g_{c}}+P_{2} V_{2}
\end{array}
$$

dengan :

$$
\begin{array}{ll}
\mathrm{U} & : \text { energi dalam (Joule) } \\
\mathrm{v} & : \text { kecepatan fluida }(\mathrm{m} / \mathrm{s}) \\
\mathrm{m} & : \text { massa fluida }(\mathrm{kg}) \\
\mathrm{g} & : \text { kecepatan gravitasi }\left(\mathrm{m} / \mathrm{s}^{2}\right) \\
\mathrm{h} & : \text { ketinggian }(\mathrm{m}) \\
\mathrm{P} & : \text { tekanan }(\mathrm{Pa}) \\
\mathrm{q} & : \text { energi panas (Joule) } \\
\mathrm{W} & : \text { kerja (Joule) }
\end{array}
$$

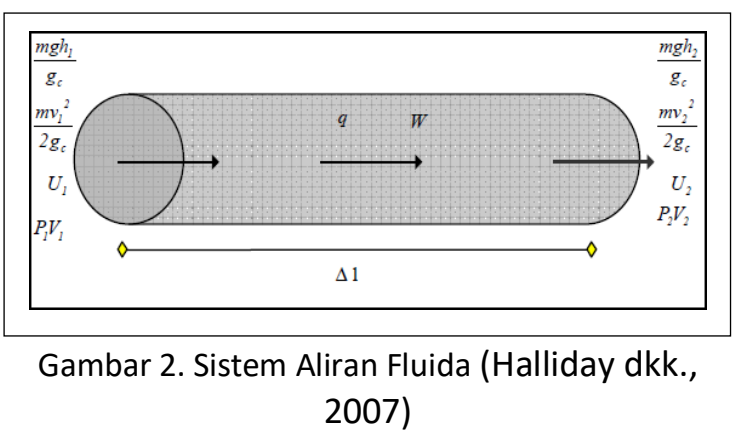

Salah satu manifestasi yang terdapat di Cisolok merupakan geyser (CSO1, CSO2) yang memiliki ketinggian sekitar 3 meter, $\mathrm{pH} 8$, dan suhu berkisar $93^{\circ} \mathrm{C}-98^{\circ} \mathrm{C}$. Selain mata air panas, terdapat juga endapan sinter dan batuan teralterasi, serta terdapat 20 kelompok mata air panas yang umumnya mempunyai temperatur tinggi $\left(71^{\circ} \mathrm{C}\right.$ hingga $100^{\circ} \mathrm{C}$ ), dengan $\mathrm{pH} 6,4-7,4$ dan debit antara 5-60 liter/menit (Abdillah dkk., 2017).

Kemunculan batuan teralterasi diperkirakan dikontrol oleh struktur berarah timur laut-barat daya dan barat laut-tenggara. Mata air panas ini berasosiasi dengan endapan sinter karbonat endapan sinter karbonat ini merupakan hasil kegiatan Resen, sedangkan batuan teralterasi diduga berkaitan dengan kegiatan zaman Tersier.

Adapun mengenai hasil analisa survei geokimia diperlihatkan pada tabel dibawah ini

Tabel 1. Survei Geokimia Cisolok (Abdillah dkk., 2017)

\begin{tabular}{|l|l|}
\hline Keterangan & Air Panas Cisolok \\
\hline $\mathrm{Cl}(\mathrm{ppm})$ & $263,0-366,0$ \\
\hline $\mathrm{HCO}_{3}(\mathrm{ppm})$ & $197,5-235,0$ \\
\hline $\mathrm{Cl} / \mathrm{HCO}_{3}$ & $2,3-2,7$ \\
\hline $\mathrm{T}\left({ }^{\circ} \mathrm{C}\right)$ & $93,0-98,0$ \\
\hline Debit $(\mathrm{l} / \mathrm{m})$ & $0,1-25,0$ \\
\hline
\end{tabular}

\section{Pipa Penyalur Uap Panas}

Heat losses atau kehilangan panas adalah kejadian yang pasti terjadi dalam aliran fluida hidrotermal dalam pipa. Tetapi dengan penambahan insulator yang melapisi PSP-MAP tersebut dapat diminimalisir dengan penambahan insulator. Ketebalan insulator tergantung pada seberapa tinggi heat losses yang terjadi pada PSP-MAP. Model heat losses ditentukan berdasarkan perpindahan panas dalam pipa ke dinding pipa dan perpindahan panas dari dinding pipa ke udara luar sesuai dengan bentuk penampang PSP-MAP pada Gambar 3 (Isnani, 2005). 
Model Heat Losses (Q) yang dipakai pada penelitian ini adalah sebagai berikut :

$$
Q=\frac{k_{1}\left(T_{i}-T_{w}\right)}{\ln \left(\frac{r_{3}}{r_{2}}\right)}+2 \pi r_{3} h_{0}\left(T_{w}-T_{a}\right) \Delta L
$$

dengan:

$k_{1} \quad$ : Konduktivitas Thermal Insulator $\left(\mathrm{Wm} /{ }^{\circ} \mathrm{C}\right)$

$T_{i} \quad$ : Suhu bagian awal $\left({ }^{\circ} \mathrm{C}\right)$

$T_{w}$ : Suhu bagian tengah $\left({ }^{\circ} \mathrm{C}\right)$

$T_{a}$ : Suhu bagian luar $\left({ }^{\circ} \mathrm{C}\right)$

$\Delta L$ : Selisih panjang pipa (m)

$r_{2} \quad$ : Panjang jari-jari pipa bagian dalam $(\mathrm{m})$

$r_{3} \quad$ : Panjang jari-jari pipa bagian luar $(\mathrm{m})$

$h_{0}$ : Koefisien transfer panas $(\mathrm{kJ} / \mathrm{kg})$

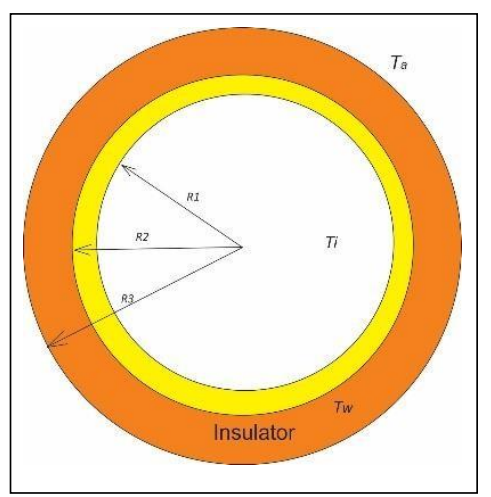

Gambar 3. Bentuk Penampang PSP-MAP

(Corel Draw, 2019)

Berdasarkan batasan masalah yang diajukan bahwa PSP-MAP yang digunakan adalah PSP-MAP horizontal dan berbentuk tabung, maka diperoleh energi potensialnya nol dan berdasarkan konsep termodinamika maka persamaan (2) menjadi persamaan aliran uap pada PSP-MAP dapat dirumuskan sebagai berikut:

$$
\frac{d P}{d L}=\frac{\left(\frac{d P}{d L}\right)_{g a s}}{1-E k}=\frac{\frac{f_{M} \rho_{n} v_{m}^{2}}{2 g_{c} d}}{1-\left(\frac{\rho_{n} v_{m} v_{s g}}{g_{c} P}\right)}
$$

dengan

$N_{R e}=\frac{\rho_{n} v_{m} d}{\mu}, f_{M}=\frac{1}{\left(1.14-2 \ln \left(\frac{\varepsilon}{d}+\frac{21.25}{N_{R e}^{0.9}}\right)\right)^{2}}$

dengan:

dP : Perubahan Tekanan ( $\mathrm{Pa})$

$\mathrm{dL} \quad$ : Perubahan Panjang $(\mathrm{m})$

$E_{k} \quad$ : Energi Kinetik (Joule)

$\mathrm{f}_{\mathrm{M}} \quad$ : Faktor Gesekan Moody

$\rho_{n} \quad$ : Densitas Fluida $\left(\mathrm{kg} / \mathrm{m}^{3}\right)$ $v_{m}:$ Kecepatan Fluida $(\mathrm{m} / \mathrm{s})$

$\mathrm{g}_{\mathrm{c}} \quad$ : Percepatan Gravitasi $\left(\mathrm{m} / \mathrm{s}^{2}\right)$

d : Ketebalan $(\mathrm{m})$

$\mathrm{P}$ : Tekanan $(\mathrm{Pa})$

$\mathrm{N}_{\mathrm{Re}}$ : Bilangan Reynold

$\varepsilon \quad:$ Kekasaran Pipa (c)

$\mu \quad$ : Viscositas Air (mPA.s)

Pemilihan jenis pipa pada umumnya terdiri dari berbagai macam pipa yang dipakai untuk panas bumi, beberapa pipa tersebut yaitu pipa Polyethylene, pipa High Density Polyethylene (HDPE), pipa PVC, pipa CPVC. Pipa Polyethylene merupakan salah satu pipa yang paling umum diketahui dan digunakan oleh kontraktor panas bumi, pipa PE dapat dibuat menjadi lurus atau melengkung (elastisitas tinggi), memberikan keserbagunaan untuk digunakan tidak hanya sebagai sumur tradisional tetapi juga dalam konfigurasi "Slinky". Pipa polyethylene memiliki karakteristik fisik yang baik, tidak mudah rusak dan bahkan bisa bertahan sampai suhu $60^{\circ} \mathrm{C}$, tetapi pipa Polyethylene tidak dapat dilem dan dihubungkan seperti jenis pipa lainnya yaitu "Heat Fused". Proses ini tidak sulit, tetapi kontraktor harus dilatih tentang hal itu dan juga harus memiliki peralatannya. Pipa Polyethylene memiliki peringkat tekanan di atas rata-rata, tetapi tidak cukup untuk digunakan di sumur vertikal yang lebih dalam. Kemudian ada High Density Polyethylene yang merupakan salah pengembangan jenis produk dari bahan baku polyethylene, Pipa HDPE mempunyai densitas lebih tinggi ketimbang pipa PE-80, Pipa HDPE mempunyai kekakuan yang lebih baik, sifat termal, dan ketahanan kimia. Pipa HDPE pun bisa bertahan selama 50, 75, bahkan 100 tahun. Pipa HDPE hadir dalam berbagai tingkatan, tetapi sebagian besar sangat kaku dan ideal untuk bidang sumur horizontal, namun dapat dapat tahan terhadap tekanan yang tinggi, dan memberikan kualitas yang sama dengan pipa Polyethylene, tetapi juga harus melewati proses "Heat Fused". Tetapi dari kelebihan yang di miliki oleh pipa HDPE, pipa ini mempunyai harga yang relatif lebih mahal dari pipa PP (polyethylene). Terlepas dari polyethylene terdapat juga pipa PVC yang berbahan dasar Polyvinyl Chloride, maka kadang disebut pula dengan pipa plastik. Pipa PVC merupakan dari beberapa pipa yang paling sering digunakan dalam konstruksi perumahan. Biasanya digunakan untuk perpipaan yang di bawah tekanan, meskipun 
memiliki peringkat tekanan yang memiliki reputasi baik. Selain itu, juga digunakan untuk membawa limbah sanitasi dan limbah pembuangan umum, Pipa PVC memiliki ketahanan yang baik terhadap banyak bahan kimia, dan tidak akan mudah rusak. Pipa PVC mudah dipasang, dan juga ringan. Tapi pipa PVC tidak elastis dan tidak resisten terhadap tekananan dan temperatur yang berlebih. Selain PVC ada juga CPVC yang merupakan opsi perpipaan berbiaya rendah yang cukup tetapi memiliki ketahanan kimia yang lemah. Pipa ini memiliki peringkat tekanan yang baik, dan datang dalam banyak konfigurasi. Mirip dengan pipa PVC, pipa tersebut menggunakan perekat untuk membuat sistem perpipaan tertutup, sehingga tidak ideal untuk loop kontinu.

\section{Batasan Masalah}

Untuk mempermudah penyelesaian desain PSP-MAP, digunakan beberapa asumsi dan parameter. Adapun beberapa asumsi dan parameter yang digunakan pada penelitian kali ini adalah sebagai berikut :

1. Fluida dianggap mengikuti sifat-sifat termodinamika murni.

2. PSP-MAP berbentuk horisontal.

3. Penggunaan insulator dalam satu PSP-MAP dianggap sama.

4. Ukuran PSP-MAP tidak mengalami pemuaian dan telah ditentukan dari awal, sehingga kekasaran pipa dan diameter pipa tidak terjadi perubahan.

5. Aliran fluida steady-state.

6. Saat fluida mengalir dalam PSP-MAP dianggap selalu dalam keadaan satu rasi.

7. Perubahan tekanan dianggap sama di semua tempat.

\section{METODOLOGI}

\section{Analisis Karakteristik Fluida Hydrothermal untuk} Pemilihan Material PSP-MAP

Tinjauan untuk pemilihan material PSP-MAP didasarkan pada karakteristik dari fluida hidrotermal yang ada di Cisolok. Berdasarkan literatur yang ada, diketahui beberapa jenis pipa yang sering digunakan di daerah geothermal adalah Pipa Polyethylene, Pipa High Density Polyethylene (HDPE), Pipa PVC dan Pipa CPVC. Adapun untuk menentukan material PSP-MAP yang cocok dengan karakteristik fluida hidrotermal yang ada di Cisolok, kami menggunakan metode Kepner-Tregoe Decision Analysis atau biasa disebut KTPA (Kepner \& Tregoe, 1958) dengan parameter sebagai berikut :

1. Biaya investasi (Primer)

2. Kelenturan dan Posisi Horizontal (Primer)

3. Suhu (Sekunder)

4. Tekanan (Sekunder)

5. Ketahanan terhadap Kandungan Kimia (Sekunder)

6. Daya Tahan dan Kekuatan (Sekunder)

Dengan menganalisa dari segi biaya investasi, kelenturaan dan posisi horizontal sebagai komponen primer dengan cara diambil deskripsi berdasarkan kelayakan jenis pipa (Ya atau Tidak) terhadap parameter primer yang ditentukan, kemudian dieliminasi salah satu jenis pipa yang tidak memenuhi syarat keterjangkauan harga yang relatif, kelenturan dan posisi horizontal yang kemudian akan dianalisa lebih lanjut jenis pipa yang tidak tereliminasi terhadap parameter sekunder dengan memberikan nilai terbaik berdasarkan parameter tersebut yang akan menghasilkan nilai kumulatif dari seluruh parameter yang ditetapkan dan yang akan dipilih sebagai material PSP-MAP.

\section{Optimasi Heat Loss Terhadap Ketebalan Insulator}

Pada persamaan (2) merupakan persamaan gradien tekanan total dan gradien tekanan karena gesekan. Pada persamaan tersebut menuntut untuk menentukan ukuran diameter PSP-MAP yang ideal karena jika diameternya terlalu kecil maka akan terjadi gesekan yang besar antar partikel, sehingga akan terjadi heat losses yang cukup besar dan jika diameter terlalu besar maka biaya investasi PSPMAP akan tinggi. Optimasi yang dilakukan adalah melihat hubungan antara ketebalan insulator dan heat losses, sehingga pada titik tertentu akan menekan laju heat losses. Optimasi ini dilakukan dengan menggunakan metode derivatif yang dibantu dengan software POD 1.0.

\section{Optimasi Biaya Investasi}

Dalam menentukan tebalnya insulator, harus memerhatikan biaya investasi yang dikeluarkan. Semakin besar ketebalan plat insulator, semakin besar biaya investasi. Optimasi yang dilakukan adalah melihat hubungan antara ketebalan insulator dan biaya investasi, sehingga pada titik tertentu akan meminimalkan nilai dari biaya investasi. Optimasi ini dilakukan dengan 
menggunakan metode derivatif yang dibantu dengan software POD 1.0. Adapun parameter yang mempengaruhi biaya investasi (Isnani, 2005):

1. Biaya Pipa

Biaya pipa ditentukan berdasarkan berattotal pipa tersebut dan dirumuskan dalam persamaan berikut:

$$
\frac{\pi}{4} \cdot \text { L. } \rho_{\text {material }} \cdot C_{\text {pipa }}\left(d_{2}^{2}-d_{1}^{2}\right)
$$

2. Biaya Aluminium

Biaya alumunium ditentukan berdasarkan luas permukaaan pipa yang dilapisi insulator tersebut dan dirumuskan sebagai berikut:

$$
\begin{gathered}
\frac{\pi}{4} . L . C_{i n s}\left(d_{3}^{2}-d_{2}^{2}\right) \\
\frac{\pi}{4} \text {. L. } C_{\text {ins }}\left(\left(d_{2}+2 h_{\text {ins }}\right)^{2}-d_{2}^{2}\right)
\end{gathered}
$$

3. Biaya Insulator

Biaya insulator ditentukan berdasarkan luas insulator tersebut dan dirumuskan sebagai berikut:

$$
\begin{gathered}
\pi \cdot d_{3} \cdot \text { L. } C_{a l m} \\
\pi \cdot\left(d_{2}+2 h_{\text {ins }}\right) \cdot \text { L. } C_{a l m}
\end{gathered}
$$

4. Biaya Heat Losses

Biaya heat losses ditentukan berdasarkan heat losses yang terjadi pada pipa dan dirumuskan sebagai berikut:

$$
\begin{aligned}
& \text { (Total waktu).Q.10-3. } C_{\text {steam }} \\
& \text { (365.24).Q. } 10^{-3} \cdot C_{\text {steam }}
\end{aligned}
$$

Mengenai biaya investasi adalah penjumlahan dari biaya pipa, biaya alumunium, dan biaya insulator. Adapun mengenai biaya maintenance adalah biaya untuk mencegah heat losses. Dengan demikian dapat diketahui bahwa biaya total investasi yang harus dikeluarkan selama 1 tahun dapat dirumuskan sebagai berikut :

\section{[Biaya Investasi] + [Biaya Heat Losses]}

\section{HASIL DAN PEMBAHASAN}

Analisis Karakteristik Fluida Hydrothermal untuk Pemilihan Material

Berdasarkan hasil deskripsi dari berbagai literatur yang ada, diketahui bahwa hasil analisa KT-DA sebagai berikut:

\begin{tabular}{|c|c|c|c|c|}
\hline Primer & PP & HDPE & PVC & CPVC \\
\hline Biaya Terjangkau & Ya & Ya & Ya & Ya \\
\hline Kelenturan dan Posisi Horizontal & Ya & Ya & Tidak & Ya \\
\hline
\end{tabular}

\begin{tabular}{|c|c|c|c|c|c|c|c|}
\hline \multirow{2}{*}{ Sekunder } & \multirow{2}{*}{ Bobot } & \multicolumn{2}{|c|}{ PP } & \multicolumn{2}{c|}{ HDPE } & \multicolumn{2}{c|}{ CPVC } \\
\cline { 3 - 8 } & $\begin{array}{c}\text { Nilai } \\
\text { Kriteria }\end{array}$ & $\begin{array}{c}\text { Nilai } \\
\text { Akumulasi }\end{array}$ & $\begin{array}{c}\text { Nilai } \\
\text { Kriteria }\end{array}$ & $\begin{array}{c}\text { Nilai } \\
\text { Akumulasi }\end{array}$ & $\begin{array}{c}\text { Nilai } \\
\text { Kriteria }\end{array}$ & $\begin{array}{c}\text { Nilai } \\
\text { Akumulasi }\end{array}$ \\
\hline Suhu & 7 & 7 & 49 & 8 & 56 & 8 & 56 \\
\hline Tekanan & 8 & 6 & 64 & 7 & 56 & 6 & 48 \\
\hline $\begin{array}{c}\text { Ketahanan } \\
\text { Tehadap } \\
\text { Kandungan } \\
\text { Kimia }\end{array}$ & 5 & 6 & 30 & 9 & 45 & 3 & 15 \\
\hline $\begin{array}{c}\text { Daya tahan dan } \\
\text { Kekuatan }\end{array}$ & 4 & 6 & 24 & 8 & 32 & 4 & 16 \\
\hline \multicolumn{2}{|c|}{ Total } & \multicolumn{2}{|c|}{167} & \multicolumn{2}{|c|}{189} & \multicolumn{2}{|c|}{135} \\
\hline
\end{tabular}

Keterangan :

PP : Polyethylenne

HDPE : High Density Polyethylene

PVC : Poly Vinyl Chloride

CVPC : Cholorinated Poly Vinyl Chloride

Oleh karena itu, pemilihan material didasarkan pada nilai akumulasi terbaik dari 4 jenis material pipa yang dianalisis. Adapun material yang dipilih adalah material pipa berjenis HDPE dengan perolehan akumulasi nilai adalah 189.

\section{Optimasi Heat Loss Terhadap Ketebalan Insulator}

Sesuai dengan persamaan (3), heat losses akan berbanding terbalik dengan ketebalan insulator. Berdasarkan hasil komputasi dengan software POD 1.0 yang ditunjukkan pada gambar 4 , diketahui bahwa semakin tebal insulator, semakin kecil heat losses yang terjadi, sehingga terbukti secara kevalidan. Adapun ketebalan yang memiliki optimasi baik dalam menjaga terjadinya heat losses terletak pada ketebalan lebih dari $0,3 \mathrm{~m}$ atau $30 \mathrm{~cm}$. Namun ketebalan insulator berpengaruh pada biaya investasi yang akan dikeluarkan, sehingga hal tersebut harus diperhitungkan. Hal tersebut akan dibahas pada optimasi biaya invetasi.

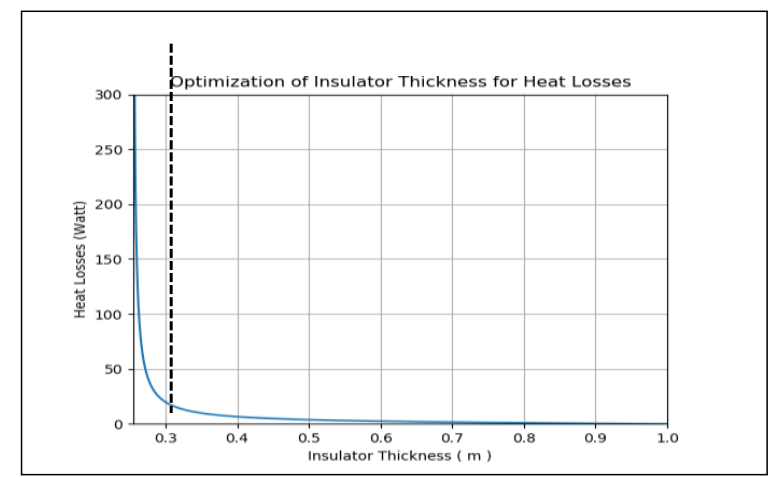

Gambar 4. Optimasi Ketebalan Insulator terhadap Heat Loss

\section{Optimasi Biaya Investasi}

Sesuai dengan model biaya yang telah dirumuskan pada persamaan (8), maka terlihat bahwa semakin tebal insulator, semakin besar biaya investasi yang harus dikeluarkan. Hal tersebut divalidasi dengan 
hasil komputasi menggunakan software POD 1.0 pada gambar 5. Kemudian dengan menggunakan beberapa parameter dan asumsi yang digunakan (ditentukan berdasarkan literatur terbaru) dan diolah dengan menggunakan software POC 1.0, diperoleh tebal insulator yang optimal sebesar 0,382 $\mathrm{m} / 38,2 \mathrm{~cm}$ dengan biaya sebesar $\$ 142,065 / \mathrm{m}$ atau dalam rupiah adalah Rp. 2.009.226,719/m (belum termasuk biaya maintenance) dalam satu tahun

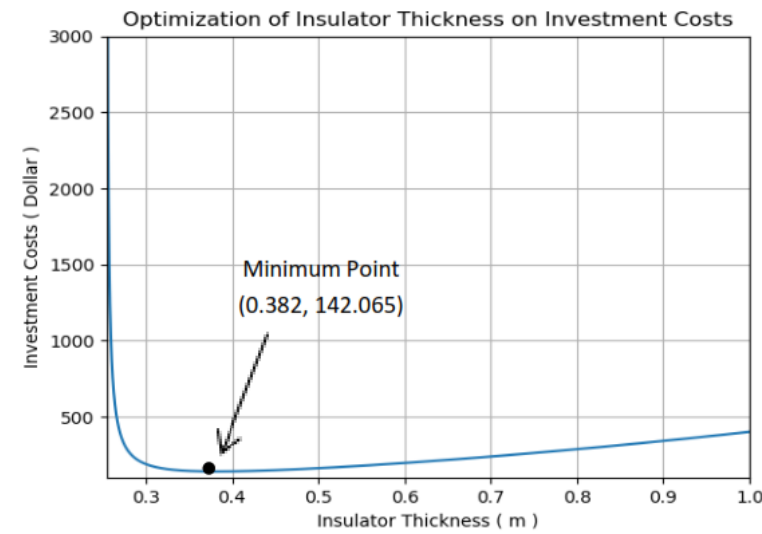

Gambar 5. Optimasi Ketebalan Insulator terhadap Biaya Investasi

\section{PENUTUP}

\section{Simpulan dan Saran}

Dengan demikian dapat disimpulkan bahwa desain PSP-MAP yang cocok untuk diaplikasikan di daerah Cisolok adalah sebagai berikut :

1. Pemilihan material PSP-MAP adalah jenis pipa berbahan HDPE.

2. Ketebalan insulator minimal yang dipilih untuk menekan laju heat losses adalah ketebalan diatas $0,3 \mathrm{~m}$ atau tepatnya sekitar $0,382 \mathrm{~m}$.

3. Biaya investasi yang dikeluarkan berdasarkan parameter yang telah ditentukan adalah sebesar $\$ 142,065 / \mathrm{m}$ atau dalam rupiah adalah Rp. Rp. 2.009.226,719/m (belum termasuk biaya maintenance) dalam satu tahun.

Adapun mengenai paper yang telah dibuat memiliki beberapa kekurangan yang harus diteliti/dikaji lebih lanjut oleh peneliti lainnya seperti:

1. Masalah kemiringan pipa karena medan di lapangan heterogen.

2. Model heat losses yang telah dibuat perlu divalidasi berdasarkan data lapangan panas bumi di daerah Cisolok.
3. Parameter/asumsi dapat ditambahkan dan dikaji lebih lanjut agar hasil analisa mendekati keadaan di lapangan

\section{DAFTAR PUSTAKA}

Abdillah, M.R., Aditio, M., Alamsyah, M.S., Haryanto, A.D. dan Rosana, M.F. (2017), "Hidrogeokimia Air Manifestasi Panas Bumi di Daerah Cisolok Cisukarame, Kabupaten Sukabumi Provinsi Jawa Barat", Geoscience Journal, Vol.1, No.3, hal. 250-259.

Ashat (1997), Pemuatan Simulator Perhitungan Kehilangan Tekanan Fluida Panas Bumi pada Pipa Alir Dua Fasa, Tugas Akhir Sarjana Teknik, Teknik Perminyakan, Institut Teknologi Bandung, Bandung.

Browne, P.R.L. (1978), "Hydrothermal Alteration in Active Geothermal Fields", Annual Review of Earth and Planetary Sciences, Vol.6, No.1, hal. 229-250. http://doi.org/10.1146/annurev.ea.06.050178. 001305.

D. H., F. dan P. R. L., B. (1994), Teaching the Teachers: Geothermal Technology, Institut Teknologi Bandung, Bandung.

Divisi Geothermal Pertamina Pusat (1986), Laporan Akhir Pemboran Sumur CSL-1 Pasir PamengpeukCisolok, Pertamina Pusat, Jawa Barat.

F., H. dan Suryantini (n.d.), Ekskursi Geothermal, Institut Teknologi Bandung, Bandung.

Fournier, R.O. dan Truesdell, A.H. (1973), "An Empirical Na-K-Ca Geothermometer for Natural Waters", Geochimica et Cosmochimica Acta, Vol.37, No.5, hal. 21.

Halliday, D., Resnick, R. dan Walker, J. (2007), GoogleBooks-ID: DTcCAAAAQBAJ, Fundamentals of Physics Extended, 10th Edition, 10th Ed., John Wiley \& Sons, Incorporated, UK.

Herdianita, R., Browne, P.R.L., Rodgers, K. dan Campbell, K. (2000), "Mineralogical and Textural Changes Accompanying Ageing of Silica Sinter", Mineralium Deposita, Vol.35, hal. 48-62. http://doi.org/10.1007/s001260050005.

Isnani (2005), "Optimasi Ketebalan Insulator Pada Jaringan Pipa Geothermal", Matematika, Vol.8, No.1, hal. 18-25.

Nicholson, K. (1993), Geothermal Fluids: Chemistry and Exploration Techniques, Springer-Verlag, Berlin Heidelberg. http://doi.org/10.1007/978-3-64277844-5. 
Oppinet (2003), Optimization on Gas and Oil Transmission and Distribution Pipeline Network, Institut Teknologi Bandung, Bandung.

Özkul, M., Varol, B. dan Alçiçek, M. (2002), "Depositional Environments and Petrography of Denizli Travertines", Mineral Res Expl Bul, Vol.125, hal. 13-29.

Permana, M.A.I. (2017), "Kajian Potensi Silica Scaling pada Pipa Produksi Pembangkit Listrik Tenaga Panas Bumi (Geothermal)", Jurnal Material dan Energi Indonesia, Vol.7, No.1, hal. 38-43. http://doi.org/10.24198/jmei.v7i01.12255.

R., D. (1998), "International Development in Geothermal Power Production", Geothermal Resources Council Bulletin,

Sujatmiko dan Santosa (1992), Geological Map of the Leuwidamar Quadrangle, Java Geological Research and Development Centre of Indonesia, Bandung, 